\title{
Limbic system hyperactivity and the phenomena of spiritual awakenings. Confronting the supernatural through the neural networks
}

\begin{abstract}
Spiritual awakenings tend to be associated with the religious rapture regardless of the spiritual path one decides to follow and are defined as temporary experiences whose main characteristic is the intensified sense of unity with the sacred. The nature of these particular phenomena gives rise to the need to carry out the in-depth analysis of the human responsiveness pattern in relation to the external stimuli, especially within the context of a religious experience. The limbic system, believed to be the headquarters of human emotions, tends to be easily activated, both verbally and non-verbally, and such activation may influence human behavior to a great extent. The principal objective of this paper is to provide a detailed classification of awakening experiences as well as to focus on the role of the amygdala and hippocampus in the production of particular religious experiences such as spiritual visions, speaking in the tongues or astral projections.
\end{abstract}

Keywords: limbic system, amygdala, hippocampus, enkephalins, spiritual awakenings, temporal lobe, right cerebral hemisphere

\section{Awakening experiences}

ccording to Steve Taylor, ${ }^{1}$ awakening experiences are phenomena of various
nature and that is why, ascribing only the spiritual dimension to them, especially

${ }^{1}$ S. Taylor, Spontaneous Awakening Experiences: Beyond Religion and Spiritual Practice, “The Journal of Transpersonal Psychology” Vol. 44, No.1, 2012, pp. 74-75. 
if the term spiritual relates to a particular religion, might be considered improper. Nonetheless, since this study concentrates mainly on the religious content, referring to one's spirituality in this paper, means solely and exclusively one's religious background, leaving aside any additional context.

Before discussing individual awakening experiences as well as their triggers, the appropriate definition of the above-mentioned phenomena should be provided. Taylor defines it as

An experience in which our state of being, our vision of the world and our relationship to it are transformed, bringing a sense of clarity, revelation and well-being in which we become aware of a deeper (or higher) level of reality, perceive a sense of harmony and meaning, and transcend our normal sense of separateness from the world. ${ }^{2}$

Bonnie Greenwell ${ }^{3}$ noticed that the awakening experience leads to the state of enlightenment compared to the form of liberation. The concept of liberation was previously taken into consideration by the Hindu tradition which emphasizes the necessity of purifying the soul. Regardless of the type of the awakening, all of them have one feature in common, namely, the spiritual rebirth accompanied by the feeling of bliss. ${ }^{4}$ As a result, it seems that one's new self, understood as conversion, comes into being. Apart from emphasizing the process itself, a particular individual's reaction to this phenomenon ought to be considered. The emergence of something unexpected may trigger uncontrolled responses, ranging from pure happiness to an intense disappointment, especially if this pleasant condition does not last long. Furthermore, one focuses on their relationship between the self and perceiving the world as a point of reference.

The problem of public experiencing in front of others became noticeable when Christian charismatics, namely Catholics as well as Neo-Pentecostals, put emphasis on implementing the sola experientia motto under which one's faith depends on the degree of their intimacy with Jesus Christ and the Holy Spirit. In the early '80s, Christian charismatic leaders from the USA started to organize healing ministries on a large scale and the main purpose of those meetings was to prove the presence of the supernatural among the gathered audience. Andrzej Kobyliński ${ }^{5}$ underlined the fact that for Neo-Pentecostals, the tendency to depend on the Holy Ghost as well as

2 Ibidem.

3 B. Greenwell, When Spirit Leaps. Navigating the Process of Spiritual Awakening, Raincoast Books, Oakland 2018, pp. 16-17.

4 S. Taylor, Exploring Awakening Experiences: a Study of Awakening Experiences in Terms of Their Triggers, Characteristics, Duration and After-Effects, “The Journal of Transpersonal Psychology” Vol. 49, No. 1, 2017a, pp. 56-57.

5 A. Kobyliński, Etyczne Aspekty Współczesnej Pentekostalizacji Chrześcijaństwa [The Ethical Aspects of Today’s Pentecostalization of Christianity], "Studia Philosophiae Christianae” 3(50)/2014, pp. 104-105. 
the expected miracles, could be equated to a completely new vision of religion as well as morality.

In Hinduism, spiritual awakenings are associated with the inner experience and thus, they are regarded as personal paths the practitioner has to follow in order to achieve the state of self-realization and the unification with the supreme Reality. ${ }^{6}$ Although the main purpose of the charismatic healing ministries being mostly miracle-oriented as well as their conduct, differ from the principal objective of the Hindu Shaktipat to a great extent, surprisingly, in both cases identical manifestations of the supernatural can be easily observed. Moreover, bearing in mind the biblical descriptions of the Holy Spirit and the main features of the Hindu kriyas, in other words, the uncontrolled body movements, it can be assumed that the practice of slaying in the Spirit as well as all the surrounding manifestations were adopted by Christian charismatics from Hinduism, rather than vice versa since according to numerous books on Pentecostalism, the first mention about these particular phenomena comes from the beginning of the $19^{\text {th }}$ century.

Last but not least, it is worth noticing that what Christians and the followers of Hinduism have in common, is the so-called limbic system with its amygdala as well as hippocampus playing major roles. The paleomammalian cortex is in charge of the physiology of emotions including fear, ecstasy or the euphoria, and on the basis of its neuroanatomy, it seems to be obvious that stimulating particular structures of the limbic system may result in the emergence of specific responses.

Therefore, what is the connection between the phenomenon of a spiritual awakening and the hyperactivity of the limbic system? Are they mutually dependent or maybe completely independent? Are certain behavioural patterns the evidence of the supernatural interference or they are merely the outcomes of the overactivity within the right hemisphere? Is it possible to group religious experiences according to their intensity? The principal objective of this research is to provide a detailed classification of spiritual awakenings, putting considerable emphasis on the external factors, as well as to focus on the involvement of both, the amygdala and the hippocampus in the process of creating particular religious experiences such as: spiritual visions, speaking in tongues or astral projections.

\subsection{The classification of awakening experiences}

Taylor $^{7}$ differentiated between two types of temporary awakening experiences, depending on their sources. The first one, termed as homeostasis disruption (HD) refers to one's condition influenced by external factors such as sleep deprivation,

${ }^{6}$ G. Krishna, The Secret of Yoga, F.I.N.D Research Trust, The Kundalini Research Foundation, ltd., Ontario/Norton Heights 1990.

7 S. Taylor, The Sources of Higher States of Consciousness, "The International Journal of Transpersonal Studies” Vol. 24, 2005, pp. 48-59. 
fasting, prolonged pain, psychedelic drugs or self-mutilation. These were classified as the states of high arousal, and what seems to be worth mentioning is the fact that they had previously been defined by Roland Fischer ${ }^{8}$ as the ergotropic higher states of consciousness. Secondly, there is also another type of a temporary awakening experience, the one of low arousal and identified by Taylor ${ }^{9}$ as the state of intensified and stilled life-energy (ISLE state). Similarly to the above-mentioned condition, the low arousal type had been formerly described by Fischer ${ }^{10}$ and referred to as the trophotropic higher state of consciousness.

\subsubsection{Homeostasis disruption}

With reference to what has been written above, homeostasis disruption appears to be the condition resulting from the impact of the external stimuli on the human body. These external agents unquestionably have the potential to affect either one's physical state or their psychological well-being. In such cases, the affected individual is no longer able to cope with the daily routine, as all the attention is focused on the problem itself. Taylor ${ }^{11}$ observed that maintaining homeostasis may be automatic (involuntary) and self-induced (voluntary). The former applies to breathing or sweating whereas the latter takes the fact of performing physical activities into consideration, namely, eating or sleeping. One of the main causes of homeostasis disruption which is the so-called psychological turmoil will be further discussed in details.

As has been shown by Oswald ${ }^{12}$ in his in-depth research, one of the reasons for suffering the internal imbalance might be the condition of sleep deprivation leading to the symptoms that could be compared with those typical of schizophrenia. Furthermore, Taylor ${ }^{13}$ in his study, provided the example of the phenomenon previously defined by Ernest Becker ${ }^{14}$ as the raw experience of the world which relates to the manner a particular individual deprived of proper sleep perceives the reality. Taylor ${ }^{15}$ focused on the experience reported by a nurse working night shifts who on her way back home had come into contact with tree leaves. Her awareness of the leaves in the sense of their vividness as well as their movements was more intense than usual.

Another reason for homeostasis disruption is closely related to the individual's religious beliefs as well as the accompanying practices. Ascetism is usually associated

${ }^{8}$ R. Fischer, A Cartography of the Ecstatic and Meditative States, „Science” Vol. 174, 1971, pp. 59-66.

9 S. Taylor, The Sources..., pp. 48-59.

${ }^{10}$ R. Fischer, A Cartography..., pp. 59-66.

11 S. Taylor, The Sources..., pp. 49-50.

12 I. Oswald, Sleep, Penguin, Harmondsworth 1970.

13 S. Taylor, The Sources..., pp. 49-50.

${ }^{14}$ E. Becker, The Denial of Death, Free Press, New York 1973.

${ }^{15}$ S. Taylor, The Sources..., pp. 49-52. 
with depriving oneself of food and other earthly pleasures in the hopes of reaching a higher state of consciousness. In Christianity, transcending ordinary consciousness appears to be tantamount to experiencing the presence of the Almighty.

The question of pain and disability, in terms of both the physical and emotional suffering, seems to be of high importance to the present study. Regardless of the spiritual path the believer follows on a regular basis, the onset of pain evokes the sudden desire to eradicate this particular, internal obstruction. The topic of healing ministries needs to be discussed separately, however, at this point it is essential to mention the fact that the prolonged inner discomfort in Taylor's ${ }^{16}$ view, has the potential to trigger the awakening experience. He provided the example of a writer who had had a serious injury resulting in his inability to work and earn money. Such a condition, namely, the physical pain combined with the emotional suffering, led to his entering the higher state of consciousness:

I suddenly found things began to happen. It was as if my entire being had been clenched in a tight fist and suddenly the fist opened up and let go completely. Everything dropped away. I began seeing and experiencing a kind of upwelling or emanation inside me. It was in front of my eyes, but also inside my eyes and inside my body, and it started flowing upward. It was emptiness, the void, but it was luminous. It was just a current of bliss. Over the next few hours, it became more and more intense. ${ }^{17}$

Pranayama exercises which are typical of yoga may also cause homeostasis disruption due to the fact that they focus on the shift in breathing patterns. In other words, automatic breathing which is connected with biological functioning belongs to the above-mentioned, involuntary category whereas the practice of influencing the normal process can be perceived as voluntary. Again, similarly to the former instances, exposing one's body to an external factor whose features are thought of as detrimental in the longer term, may lead to a serious, internal imbalance whose final outcome will be the awakening experience.

Taking all the above-discussed cases into consideration, it can be stated that homeostasis disruption unquestionably contributes to evoking the higher states of consciousness, specified by Taylor ${ }^{18}$ as the feeling of an intensified perception of the outer world and the sense of crossing all existing boundaries.

\subsubsection{Intensification and stilling of life-energy (ISLE)}

Awakening experiences can also be triggered by the stimuli of a completely different origin. In consequence, the manifestations of the supernatural belong to a separate category. The ISLE state, where ISLE stands for intensification and stilling of life-energy, appeals to the inner consciousness as well as the peaceful, relaxing

16 Ibidem.

17 S. Taylor, Out of the Darkness. From Turmoil to Transformation, Hay House UK Ltd. 2011.

18 S. Taylor, The Sources..., pp. 48-59. 
practices $^{19}$. These practices include: meditation, praying, contact with nature, listening to music and many other that are quietness-centred. The principal objective of performing such activities is to tame the so-called thought-chatter ascribed to most of the human, mental processes. In other words, the life-energy being formerly consumed on cognition or perception, now has the chance to be stored and thus the individual experiences the surplus of it. Arthur Deikman ${ }^{20}$ referred to such a condition using the term: deautomatization of perception.

The problem of life-energy has also been tackled by Michael Washburn. ${ }^{21}$ who differentiated between: the psychic energy, libido and spiritual power. He considered the psychic energy as the one of highest importance for a human being due to its qualities compared to a fuel. In this particular case, it is the fuel of a conscious life. According to Washburn ${ }^{22}$, the psychic energy has the potential to create the highly energized mental states to attract the ego as well as to dissolve it. In his research, he concentrated on the idea of disillusionment when it comes to the external world and this is the reason why he commented on the practice of withdrawing from this earthly sphere. He emphasized the fact that the energy that had formerly been responsible for creating vivid images, now returns to the deep psyche which is believed to be its source.

Taylor $^{23}$ discussed on the above-mentioned surplus of energy within the context of awakening experiences, providing numerous examples based on his own research. He noticed that apart from the emotional imbalance described earlier in this study, contact with nature had also been one of the main triggers:

The sun was setting and I was watching it go down. I felt everything in the world was there, at this moment. The sunlight was so incredibly bright and pure and beautiful, and the whole sky with the clouds and the blue. That blue was the smoothest and purest blue I've ever seen. I could see everything about the clouds, as if they had a whole new dimension. It seemed so simple and so right. I felt how easy it would be to be happy. ${ }^{24}$

Bearing in mind all the stimuli which evoke particular awakening experiences, it can be stated that the triggers from the external world contribute to the previously-explained homeostasis disruption whereas the „inner world”, whose main feature is the intensification of life-energy, induces the ISLE states. Furthermore, the ISLE states, unlike the homeostasis disruption, manifest themselves in the intense feeling of inner

${ }^{19}$ S. Taylor, Energy and Awakening: a Psycho-Sexual Interpretation of Kundalini Awakening, “The Journal of Transpersonal Psychology” Vol. 47, No. 2, 2015, pp. 231-232.

${ }^{20}$ A. Deikman, Deautomatization and the Mystic Experience, http://deikman.com/deautomat. html [2.01.2020].

${ }^{21}$ M. Washburn, Embodied Spirituality in a Sacred World, State University of New York Press, Albany 2003, pp. 61-90.

${ }^{22}$ Ibidem.

${ }^{23}$ S. Taylor, Spontaneous Awakening..., pp. 82-85.

${ }^{24}$ Ibidem. 
peace which is combined with the sense of finding a true Self. Only the ISLE states offer the opportunity to transform one's consciousness permanently.

\subsection{Intense psychological turmoil as the cause of permanent transformational experiences (SITEs)}

Taylor $^{25}$ in his detailed research on awakening experiences, differentiated between the states of temporary nature as well as those whose after-effects are not prone to changes or disappearance in general, namely, the so-called permanent suffering-induced transformational experiences (SITEs). As their name suggests, they tend to be evoked by various disturbances of the self-system, recognized under the common name - psychological turmoil. This particular category encompasses the following conditions: intense stress, depression, bereavement, serious illness or addictions such as alcoholism. As far as SITEs are concerned, the intensity of the turmoil seems to be more important than its type. The question which is undoubtedly worth posing relates to the concept of mutual dependence. How is it possible that the ailments with such negative connotations contribute to a positive development? In other words, how is it possible that intense unhappiness leads to the permanent change of the inner self, bearing in mind the beneficial outcome of sinking into despair?

First and foremost, the issue of narrative construction should be discussed in order to understand the human ability to deal with traumatic situations. Aaron L. Mishara ${ }^{26}$ emphasized the significance of the fact that the human subject functions on two different surfaces, that is to say, the subject-surface and the object-surface. The former operates at this particular moment whereas the latter tends to be associated with the past. The suggested distinction appears to be extremely helpful while performing the narrative act since the practice of storytelling facilitates self-transcendence. In other words, the possibility to share trauma enables the subject to separate itself from the internal imbalance, understood as turmoil. This is particularly important when it comes to mass healing ministries. During such meetings, the subject operating at this very moment detaches itself from the object of the story, associated with past events, and thus a clear distinction is made between what has already happened and what may happen from now onwards. Such an approach could be compared to stepping into a completely new reality. The subject performs the role of a narrator who stands in front of the audience with the intention of being internally purified or, in other words, experiencing spiritual catharsis.

${ }^{25}$ S. Taylor, The Peak at the Nadir. Psychological Turmoil as the Trigger for Awakening Experiences, “International Journal of Transpersonal Studies” 32(2)/2013, pp. 1-10.

${ }^{26}$ A.L. Mishara, Narrative and Psychotherapy - The Phenomenology of Healing, „American Journal of Psychotherapy” 49(2)1995, pp. 180-193. 
Taylor $^{27}$ identified two types of awakening experiences as mentioned above, namely, temporary as well as permanent, and the predominant factor on which he based his theory was the final outcome of the phenomenon or to be more precise its duration. He introduced two significant terms, these are, the primary shift and the secondary shift, with reference to the subject's spiritual growth as well as the emergence of the entirely new psychological structure.

The primary shift, typical of the permanent suffering-induced transformational experiences (SITEs), could be defined in terms of rebuilding the self-system which is similar to enlightenment. Taking Mishara's ${ }^{28}$ theory of the narrative act into account, this type of transition might be compared to the idea of the subject detaching from the object. The prolonged suffering leads to the dissolution of the so-called psychological attachments such as hopes, the sense of status, social roles or ambitions. ${ }^{29}$ This particular state is tantamount to severe ego-dissolution which manifests itself in the loss of identity. The psychic energy previously engaged in mental functions, now returns to its source in the form of a surplus. ${ }^{30}$ The impact of SITEs on the subject seems to be tremendous. First of all, the feeling of being reborn emerges. The subject takes on a new identity with a new relationship towards the external world. The same happens when it comes to embracing values and thinking of perspectives. Furthermore, Taylor's ${ }^{31}$ research provided even more detailed outcomes of SITEs such as: the reduced fear of death, decreased cognitive activity, pleasure in doing nothing and being alone or deeper awareness. Regardless of the fact whether SITEs are spontaneous or induced through the contact with the healer for instance, all of them lead to the emergence of a completely different inner-self.

The secondary shift, which is characteristic of temporary awakening experiences, is also concentrated around the self-system, however, in this case it remains intact as a unit and that is why, rebuilding is not necessary. In other words, the

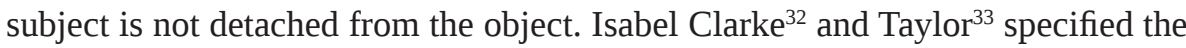
following manifestations of temporary awakening experiences:

- the feeling of unity, love and compassion;

- feelings of objectivity and reality;

- transcendence of space and time;

- a sense of sacredness;

27 S. Taylor, Exploring Awakening..., pp. 45-62.

${ }^{28}$ A.L. Miahara, Narrative and Psychotherapy..., pp. 180-193.

${ }^{29}$ S. Taylor, The Peak at the Nadir..., pp. 1-10.

${ }^{30}$ M. Washburn, Embodied Spirituality..., pp. 61-90.

${ }^{31}$ S. Taylor, Transformation Through Suffering: A Study of Individuals Who Have Experienced Positive Psychological Transformation Following Periods of Intense Turmoil, "Journal of Humanistic Psychology” XX(X), 2011, pp. 1-23.

${ }^{32}$ I. Clarke, Psychosis and Spirituality. Consolidating the New Paradigm, Wiley-Blackwell, Oxford 2010, pp. 13-14.

${ }^{33}$ S. Taylor, Exploring Awakening..., pp. 53-55. 
- deeply felt positive mood: joy, lack of fear, blessedness, peace and bliss;

- ineffability - impossibility to express oneself due to the inadequate language;

- positive change in attitude or behaviour;

- lack of mental thought chatter.

On the basis of the above-listed set of conditions, it can be assumed that the external triggers induce the internal responses whose duration according to Taylor ${ }^{34}$ ranges from days to months. Although the after-effects of such phenomena may last longer than usual, temporary awakening experiences should not be confused with the permanent transformation.

\subsection{Altered States of Consciousness (ASC): the hypnotic aspect of healing}

The practice of organizing healing ministries aims at bringing relief to those who suffer from the broadly understood pain. The prolonged illness is one of the triggers influencing the emergence of awakening experiences. The inner quietness as well as peace result from stilling of the life-energy. Hypnosis, which is famous for its calming qualities, belongs to the category defined as the Altered States of Consciousness (ASC). It is associated with the alteration of the usual mental activity after implementing the procedure known as induction. According to David A. Oakley ${ }^{35}$, the increase in absorption, reduction in thought-chatter as well as the focused attention, are the main characteristics of hypnosis. The same is true for meditation whose features will be further discussed.

Healing ministries owing to the fact that they are public, impose certain informal obligations on their participants. Generally speaking, in order for the participant to maximize their sense of belonging, all the views that are held by the leader and all the activities that are performed in public, ought to be accepted and shared without any hesitation. Moreover, ASC have the potential to influence various types of healing, however, they appear to be more successful with reference to somatizing patients than those with tumors. ${ }^{36}$ In Oakley's ${ }^{37}$ view, hypnosis consists of two, interconnected processes, namely, induction and suggestion. The former concerns a set of instructions given by the hypnotist to the subject with the intention of influencing the subject's mental behaviour or evoking particular mental strategies, such as the individual's involvement in guided imagery. The latter is a series of statements released by the hypnotist whose principal objective is to describe the

34 Ibidem.

35 D.A. Oakley, Hypnosis, Trance and Suggestion: Evidence from Neuroimaging, in Barnier J., Nash M.R. (eds), The Oxford Handbook of Hypnosis, Oxford University Press, Oxford 2008, pp. 365-392.

36 A.L. Mishara, Narrative and Psychotherapy..., pp. 180-193.

37 D.A. Oakley, Hypnotic Suggestion: Opportunities for Cognitive Neuroscience, "Nature Reviews Neuroscience” Vol. 14, 2013. 
ongoing changes in the subject's behaviour. These two stages are mutually dependent and that is why hypnotic suggestions may be applied to the participant even during the first stage. The type of hypnosis based on the interaction between the subject and the hypnotist is known as heterohypnosis whereas performing hypnosis alone is referred to as autohypnosis.

Oakley $^{38}$ took an interest in the question of hypnotic suggestibility and, as a result, he classified suggestions into three main categories, namely, ideomotor-ideosensory direct suggestions, ideomotor challenge suggestions as well as these which appear to be most significant for the present study - cognitive suggestions. Ideomotor-ideosensory suggestions cause heaviness, the ideomotor challenge suggestions apply to the individual's inability to act in accordance with their will because of the aforementioned heaviness, whereas cognitive suggestions lead to the emergence of the altered states of consciousness in the form of hallucinations. In other words, a cognitive suggestion could be defined as a powerful tool for affecting both memory and perception. Furthermore, the problem of the cooperation between the hypnotist and the subject was also tackled by Merlin Donald ${ }^{39}$ who focused on the human ability to express itself through gestures. He provided the term mimetic culture in order to prove that the human body has the potential to act as an effective communication device. With regard to what has already been said about the importance of the external stimuli when it comes to triggering particular awakening experiences, it can be assumed that the healer or the hypnotist acts as the agent who provides the external stimulus affecting the subject. In consequence, the subject's psychic energy returns to its source leading to internal quietness as well as deep relaxation, and finally, the subject, depending on their responsiveness, has the opportunity to experience the awakening phenomenon. The above-listed hypnosis techniques and their effects may account for why the participants are firmly convinced of being healed.

\section{The right cerebral hemisphere and the limbic system}

Human brain consists of two interconnected parts, namely, the left and the right hemisphere. The former is recognized as the one responsible for the organization and categorization of information together with articulatory movements ${ }^{40}$, whereas the latter is mainly associated with emotions, visual-spatial skills and awareness. These two mental systems are expected to co-operate with the intention of enabling a human being to perform daily tasks.

38 Ibidem.

39 M. Donald, Origins of the Modern Mind. Three Stages in the Evolution of Culture and Cognition, Harvard University Press, Cambridge 1991.

40 R. Joseph, The Right Cerebral Hemisphere: Emotion, Music, Visual-Spatial Skills, BodyImage, Dreams, and Awareness, “Journal of Clinical Psychology” 5(44)/1988. 
In the twentieth century, attempts have been made to define and categorize the neural networks governing emotional processes. In consequence, the term limbic system came into existence. According to Robert L. Isaacson ${ }^{41}$, the term limbic lobe was first presented in 1878 by the French anatomist, Paul Broca, and relates to a hem or border while the limbic lobe applies to the brain tissue connected with the area of the brain stem and, at the same time, located below the neocortical mantle. The original understanding of the limbic system has been extended by the American neuroscientist - MacLean - who redefined this particular issue putting emphasis on the fact that, in reality, the limbic system is a complex structure in control of emotional functioning and the practice of stimulating its specific regions influences blood pressure or the heart rate. ${ }^{42}$ Moreover, he listed the parts of the human brain systematically participating in the above-mentioned activities and thus officially comprising the limbic system. These are the amygdala, septum, pre-frontal cortex, the thalamus, hypothalamus, hippocampus and cingulate cortex. The amygdala as well as the hippocampus are of highest importance for this particular study.

The neurobiology of religious experiences focuses on the amygdaloid and hippocampal complexes within the temporal lobe due to the fact that the proper stimulation of the aforementioned structures evokes the phenomena previously associated with the manifestations of the spirits. Activating temporal lobe structures applies to both the verbal and non-verbal stimulation such as the practice of implementing the metaphorical language relating to self-preservation by religious leaders. When it comes to the non-verbal factors, they encompass the following triggers: social isolation, vestibular stimuli, smells, recalling memories or the previously-discussed fasting together with the prolonged pain. Bearing in mind the qualities of the amygdala, especially these which refer to the production of emotional states, namely, fear, depression, happiness or ecstasy, it can be assumed that a well-trained preacher or healing minister, has the potential to manage the particular individual's religious experience to a considerable extent. In other words, the Christian charismatic leader conducting a mass healing ministry, appears to be able to affect participants' responsiveness to the verbal as well as non-verbal stimuli he or she employs. Furthermore, owing to the fact that the amygdala may store memories evoked by affective states, the individual may turn out to be prone to reexperiencing them either when awake or when dreaming. According to Jo$\mathrm{seph}^{43}$, these phenomena may emerge in the form of auditory, visual, religious or spiritual imagery. To illustrate, the practice of the so-called speaking in tongues, which is typical of Christian charismatics, should be taken into consideration. In

${ }^{41}$ R.L. Isaacson, The Limbic System, Springer, New York 1982.

${ }^{42}$ P.R. Franceschini et al., The Limbic System Conception and Its Historical Evolution, "The Scientific World Journal” 11/2011, pp. 2428-2441.

${ }^{43}$ R. Joseph, The Limbic System and the Soul: Evolution and the Neuroanatomy of Religious Experience, “Zygon” Vol. 36, No. 1, 2001, pp. 105-136. 
this particular case, the implemented stimulus is obviously verbal, since the leader prepares the participants beforehand by adjusting the amplitude, pitch, and the melody of their voice. Joseph ${ }^{44}$ noted that the right hemisphere dominates over the left hemisphere with regard to interpreting as well as processing vocal triggers. The verbal stimulus provided by the leader, activates the individual's amygdala and in consequence, the individual expresses themselves linguistically, however, such an expression has nothing in common with any of the widely-recognized foreign languages.

As far as the hippocampus is concerned, it comprises the place-related neurons whose principal objective is to encode one's spatial position. To be more precise, the hippocampus may be compared to one's personal guide of the mental environment the individual acts within. When hyperactivated, the hippocampus has the potential to induce hallucinations, especially if it cooperates with the amygdala. As mentioned by Michael A. Persinger ${ }^{45}$, the plasticity of the temporal lobe, facilitates the emergence of electrical microseizures known as temporal lobe transients (TLTS) which are in fact considered to be the actual cause of mystical or religious experiences. Providing the temporal lobe with the appropriate triggers such as the environment (healing ministry for instance) combined with the metaphorical language (talking about the angels and the demons simultaneously) used by the religious leader in order to affect one's emotional state, is believed to be the reference point for the yet unexplained phenomena, recognized under the common name out-of-body experiences $(\mathrm{OBE})$. If the hippocampus bears responsibility for human spatial orientation, then it appears to be obvious that its hyperactivity gives rise to the feeling of being separated from the physical body and, at the same time, witnessing one's own life from the position of the independent observer equipped with greater awareness. Out-of-body experiences tend to be associated mainly with near-death experiences (NDE) and the process of returning to life. This particular condition differentiates between the state of floating above one's body as well as the state of floating away. The former concerns the possibility to penetrate the reality the other participants are also part of whereas the latter enables the individual to see heavens and to communicate with the dead. Joseph ${ }^{46}$ referred to the state of floating away as the astral projection. In addition, he mentioned the cases of people who had communed with three "ancient" men in order to meet their ancestors and who had experienced the ability to move at incredible speed. It is noteworthy that stimulating the amygdala as well as the hippocampus results in both changes in the spatial orientation (hallucinations, OBE, NDE) and the release of a series of positive feelings (euphoria). The emergence of rapture which results from the possibility to

${ }^{44}$ R. Joseph, The Right Cerebral..., pp. 630-673.

45 M.A. Persinger, Religious and Mystical Experiences as Artifacts of Temporal Lobe Function: a General Hypothesis, "Perceptual and Motor Skills” 57/1983, pp. 1255-1262.

${ }^{46}$ R. Joseph, The Limbic System and the Soul..., pp. 105-136. 
float away, for instance, is believed to be caused by the presence of the endogenous opiates originating from the brain tissue and known as the enkephalins. These are pantapeptides cooperating with particular opiate receptors and, what seems to be most significant, they are located in the hypothalamus which constitutes an integral part of the limbic system. The amygdala releases large quantities of enkephalins upon activation and owing to their analgesic qualities, they have the potential to reduce pain as well as transform the unpleasant sensations into positive feelings. ${ }^{47}$ Enkephalins are believed to operate similarly to the endorphins, however, their distribution differs.

When it comes to the principal characteristics of the enkephalins moving through the amygdala, it can be assumed that the miracles taking place during many healing ministries organized by Christian charismatic groups, especially when talking about the cases of spontaneous healing and the instant relief from pain, result from the process of finding as well as combining with the compatible receptors. Owing to the fact that the enkephalins belong to opioids, they tend to influence the nervous system to a great extent. The same could be said of the practice of Shaktipat and its impact on the participant's body.

\section{Conclusions}

The main purpose of the article was to provide a detailed classification of spiritual awakenings as well as to focus on the possible connections between limbic system hyperactivity and the production of particular religious experiences.

First of all, it should be noticed that spiritual awakenings differ to a considerable extent in terms of the source as well as duration. Those which are classified as internal, have the potential to last permanently whereas those triggered by the external factors are rather of temporary nature. They are referred to as the primary and secondary shift respectively.

Secondly, spiritual awakenings tend to be accompanied by a series of side-effects whose common denominator may be defined as the feeling of unity with the sacred. An individual experiencing the awakening is believed to find it difficult to even talk about their sensations and such a condition has been termed as ineffability. The individual's relationship with the external world, namely, the family environment together with the working environment, may turn out to be impossible to deal with. The fact of experiencing the enlightenment may not be properly understood by others.

Thirdly, a more detailed insight into the functioning of the limbic system with special emphasis on the amygdala as well as the hippocampus, provides explana-

${ }^{47}$ V. Clement-Jones, A. Grossman, Opiate Receptors: Enkephalins and Endorphins, "Clinics in Endocrinology and Metabolism” Vol. 12, No. 1, 1983, pp. 31-56. 
tions to the aforementioned phenomena such as speaking in tongues, which takes place during many healing ministries or group meetings organized by Christian charismatics, instant relief from pain formerly associated with the manifestations of the Holy Spirit or the religious rapture combined with out-of-body experiences. Furthermore, it should be noted that the limbic system is vulnerable to the external stimulation, both verbal and non-verbal. The former relates for instance to the metaphorical language used by a religious leader whereas the latter may be accomplished by living in seclusion or implementing certain yoga positions.

In addition, the fact of releasing large quantities of the endogenous opiates known as the enkephalins, which owing to their analgetic as well as calming qualities may affect human behavior, provides a basis for focusing attention on the question of coping with trauma. The aforementioned psychological turmoil may serve as an appropriate example. An individual suffering from depression or dealing with a traumatic event may experience the state which they will probably define as the spiritual awakening but in fact, the condition they experience results from the interaction between the endogenous opiates and their receptors located in brain tissue.

Finally, it is worth mentioning that the issues concerning the side-effects of some religious practices such as healing ministries or Shaktipat together with their scientific interpretation have not been explained yet. To be more precise, human responsiveness to the external stimuli provided by another participant (religious leader) and at the same time being automatically associated with the supernatural, requires further research. The same applies to the link between homeostasis disruption and its influence on the release of the enkephalins. What is the real source of the phenomena understood as spiritual awakenings? More attention should be paid to the problem of limbic system hyperactivity, with special emphasis put on the endogenous opiates, since it may turn out that the eagerly-worshipped spirits actually reside in the right hemisphere.

\section{References}

Becker E., The Denial of Death, Free Press, New York 1973.

Clarke I., Psychosis and Spirituality. Consolidating the New Paradigm, Wiley-Blackwell, Oxford 2010.

Csordas T.J., Elements of Charismatic Persuasion and Healing, "Medical Anthropology Quarterly” Vol. 2, No. 2, 1988.

Deikman A., Deautomatization and the Mystic Experience, http://deikman.com/deautomat. html [2.01.2020].

Donald M., Origins of the Modern Mind. Three Stages in the Evolution of Culture and Cognition, Harvard University Press, Cambridge 1991.

Fischer R., A Cartography of the Ecstatic and Meditative States, "Science” Vol. 174, 1971. 
Franceschini P.R et al., The Limbic System Conception and its Historical Evolution, “The Scientific World Journal” 11/2011.

Greenwell B., When Spirit Leaps. Navigating the Process of Spiritual Awakening, Raincoast Books, Oakland 2018.

Grossman A., Clement-Jones V., Opiate Receptors: Enkephalins and Endorphins, “Clinics in Endocrinology and Metabolism” Vol. 12, No. 1, 1983.

Isaacson R.L., The Limbic System, Springer, New York 1982.

Joseph R., The Right Cerebral Hemisphere: Emotion, Music, Visual-Spatial Skills, Body-Image, Dreams, and Awareness, “Journal of Clinical Psychology” 5(44)/1988.

Joseph R., The Limbic System and the Soul: Evolution and the Neuroanatomy of Religious Experience, “Zygon” Vol. 36, No. 1, 2001.

Kobyliński A., Etyczne Aspekty Współczesnej Pentekostalizacji Chrześcijaństwa [The Ethical Aspects of Today's Pentecostalization of Christianity], "Studia Philosophiae Christianae" 3(50)/2014.

Kobyliński A., The Global Pentecostalization of Christianity and its Ethical Consequences, “Chicago Studies” 2(55)/2016.

Krishna G., The Secret of Yoga, F.I.N.D Research Trust, The Kundalini Research Foundation, ltd., Ontario/Norton Heights 1990.

Kumar R., Kumar Larsen J., Shaktipat. Awakening of Kundalini by the Guru, New Dawn Press Group Inc., Elgin 2009.

McGuire M., Lived Religion. Faith and Practice in Everyday Life, Oxford University Press, Oxford 2008.

Mishara A.L., Narrative and Psychotherapy - The Phenomenology of Healing, “American Journal of Psychotherapy” 49(2)/1995.

Oakley D.A., Hypnosis, Trance and Suggestion: Evidence from Neuroimaging, in J. Barnier, M.R. Nash (eds), The Oxford Handbook of Hypnosis, Oxford University Press, Oxford 2008.

Oakley D.A., Hypnotic Suggestion: Opportunities for Cognitive Neuroscience, "Nature Reviews Neuroscience” Vol. 14, 2013.

Oswald I., Sleep, Penguin, Harmondsworth 1970.

Persinger M.A., Religious and Mystical Experiences as Artifacts of Temporal Lobe Function: a General Hypothesis, "Perceptual and Motor Skills" 57/1983.

Schwartz M.A., Mishara A.L., Altered States of Consciousness as Paradoxically Healing: an Embodied Social Neuroscience Perspective, in E. Cardeña, M. Winkelman (eds), Altering Consciousness: a Multidisciplinary Perspective, Vol. 2, Praeger, Santa Barbara 2011.

Taylor S., The Sources of Higher States of Consciousness, “The International Journal of Transpersonal Studies” Vol. 24, 2005.

Taylor S., Out of the Darkness. From Turmoil to Transformation, Hay House UK Ltd. 2011. Taylor S., Transformation Through Suffering: A Study of Individuals Who Have Experienced Positive Psychological Transformation Following Periods of Intense Turmoil, "Journal of Humanistic Psychology” XX(X), 2011.

Taylor S., Spontaneous Awakening Experiences: Beyond Religion and Spiritual Practice, “The Journal of Transpersonal Psychology” Vol. 44, No. 1, 2012.

Taylor S., The Peak at the Nadir: Psychological Turmoil as the Trigger for Awakening Experiences, “International Journal of Transpersonal Studies” 32(2)/2013. 
Taylor S., Energy and Awakening: a Psycho-Sexual Interpretation of Kundalini Awakening, “The Journal of Transpersonal Psychology” Vol. 47, No. 2, 2015.

Taylor S., Transformation Through Suffering: a Study of Individuals Who Have Experienced Positive Psychological Transformation Following Periods of Intense Turmoil, “Journal of Humanistic Psychology” 52(I)/2015.

Taylor S., Exploring Awakening Experiences: a Study of Awakening Experiences in Terms of Their Triggers, Characteristics, Duration and After-Effects, "The Journal of Transpersonal Psychology” Vol. 49, No. 1, 2017.

Taylor S., The Leap. The Psychology of Spiritual Awakening, New World Library, Novato 2017.

Washburn M., Embodied Spirituality in a Sacred World, State University of New York Press, Albany 2003.

Yilmazer-Hanke D., Insights into the Amygdala. Structure, Functions and Implications for Disorders, Nova Science Publishers, New York 2012.

Zubaran C., Sander J.W., Roxo M.R., Kleber F.D., Franceschini P.R., The Limbic System Conception and its Historical Evolution, “The Scientific World Journal” 11/2011. 